\title{
Marcadas pelo mercado: inserção profissional e carreira de mulheres transexuais e travestis*
}

\author{
Karolyn Marilyn de Oliveira Santos** \\ Lígia Carolina Oliveira-Silva***
}

\begin{abstract}
Resumo
Mulheres transexuais e travestis enfrentam barreiras relacionadas à transição de gênero que incidem diretamente sobre sua empregabilidade e inserção no mercado formal de trabalho, além de afetar seu planejamento de carreira. Nesse sentido, este estudo teve como objetivo investigar a inserção profissional, a percepção de barreiras e planejamento de carreira de mulheres transexuais e travestis. A partir da análise de conteúdo de entrevistas individuais constatou-se a percepção de múltiplas barreiras em função do gênero e a ausência de planejamento de carreira devido à falta de suporte.
\end{abstract}

Palavras-chave: Carreira, Barreiras, Mulheres, Transexuais, Travestis.

\footnotetext{
* Recebido em 11 de outubro de 2019, aceito em 22 de julho de 2020.

** Psicóloga pela Universidade Federal de Uberlândia (UFU), Uberlândia, MG, Brasil. karolynmarilyn@hotmail.com / https://orcid.org/0000-0002-6870-0711

****Professora de Psicologia Organizacional e do Trabalho no Instituto de Psicologia e no Programa de Pós-Graduação em Psicologia na Universidade Federal de Uberlândia (UFU), Uberlândia, MG, Brasil. Coordenadora do Grupo de estudo, pesquisa e extensão "Trabalhando com as Marias: Mulheres e Carreira" (CNPq), com projetos apoiados pela FAPEMIG. ligiacarol@ufu.br / https://orcid.org/0000-0002-7487-9420
} 
Marked by the Market: Professional Insertion and Careers of Transsexual and Transvestite Women

\begin{abstract}
Transgender and transvestite women face gender transition barriers that directly affect their employability and insertion in the formal labor market, as well as their career planning. The objective of this study was to investigate professional insertion, perception of barriers and career planning among transsexual and transvestite women. Content analysis of individual interviews found the perception of multiple gender related barriers and the absence of career planning due to lack of support.
\end{abstract}

Keywords: Career, Barriers, Women, Transgender, Transvestites. 


\section{Introdução}

A importância de planejar a carreira no mundo do trabalho no século XXI se dá a partir das diferentes percepções dos indivíduos acerca do trabalho. Anteriormente entendido como obrigação, hoje é percebido como meio para independência e autonomia; nesse sentido, considerando a entrada e permanência no campo profissional, o planejamento de carreira se torna um diferencial (Noronha; Lamas, 2014). Recentemente, mudanças importantes em comportamentos, valores sociais e inovações tecnológicas repercutem permanentemente no mercado de trabalho (Araújo, 2018).

Nesse ínterim, destaca-se a importância da carreira, que representa um conjunto de posições e trabalhos realizados, organizados num caminho flexível e explorado pelo indivíduo que faz escolhas e planeja sua vida profissional (Dutra, 2010). Planejar a carreira, portanto, significa buscar uma visão mais realista e apurada de suas competências e interesses, traçar objetivos e preferências profissionais orientados para o futuro (Dutra, 2010). Esse processo sofre influências dos familiares, das redes de relacionamento, do contexto social e do mundo do trabalho, além de motivações pessoais (Perantoni Guigen et al., 2014).

Por conseguinte, sendo o planejamento de carreira um diferencial para adentrar e se estabelecer no campo profissional, faz-se necessário atentar para a existência, disponibilidade e importância desse processo na carreira de indivíduos socialmente estigmatizados, tais como mulheres transexuais e travestis. Considerando as peculiaridades desse público, sua permanência no mercado formal de trabalho enfrenta diversas barreiras relacionadas à exclusão e o preconceito social, tais como o uso do nome social, hostilidade e assédio sexual (Martendal, 2015; Rondas; Machado, 2015). Somam-se a essas barreiras o desconhecimento por partes dos colegas $e$ organizações das mudanças necessárias para se fornecer um ambiente seguro de trabalho para transexuais, assim como percepções equivocadas que levam a queixas, adoecimentos, afastamentos, falta de colaboração e outras consequências negativas (Human Rights Campaign Foundation, 2004; Budge; Tebbe; Howard, 2010).

Aliada a tal problemática, constata-se uma persistente escassez de pesquisas relacionadas ao tema e ao público em questão, bem como a ausência de diretrizes de carreira específicas para tal (Adams; Cahill; Ackerlind, 2005). Schilt (2006) e Schilt \& Connell (2007), por exemplo, apontaram que até então não havia pesquisa conhecida que houvesse investigado no local de trabalho processos de transição de gênero e carreira de transexuais. $\mathrm{O}$ status da pesquisa e práticas efetivas para aconselhamento de carreira com indivíduos variantes de gênero é descrito como escasso, uma vez que pesquisas com esse público não são realizadas baseadas na justificativa de não haver necessidade, pois são considerados uma parcela pequena da população, além da falta de financiamento para que ocorram, e da consideração, por parte dos aconselhadores de carreira, de que a preocupação com a carreira desses indivíduos seja "trivial" (O’Neil; Mcwhirter; Cerezo, 2008).

Estudos posteriores como o de Chope e Strom (2008) fizeram considerações críticas sobre carreira e emprego, destacando estratégias para o aconselhamento em carreira com clientes transgêneros. Budge, Tebbe e Howard (2010), por sua vez, analisaram as experiências de trabalho de transgêneros, os processos de transição e tomada de decisão na carreira, apontando que ambos refletem complexidades, dado que o processo de transição no trabalho difere da transição na vida pessoal. Em seus resultados, notaram que os participantes iniciaram a transição no trabalho muito tempo após o início em suas vidas privadas, devido à apreensão em relação aos impactos negativos que sobreviriam em suas carreiras.

Já pesquisas como as de Chavez-korell e Johnson (2010) enfatizam a necessidade de se investigar a temática de carreira junto a transgêneros, uma vez que apontam a importância do treinamento de orientadores e de serviços de aconselhamento específicos para a comunidade transgênero. De maneira similar, Brown et al (2012) evidencia as experiências de mulheres transexuais no mercado de trabalho, fornecendo orientações para psicólogos de aconselhamento. Budge, Tebbe e Howard (2010), por sua vez, justificam a necessidade de mais pesquisas que documentem as experiências de indivíduos transgêneros, para que os psicólogos detenham embasamento teórico suficiente ao realizar aconselhamentos de carreira ou terapêuticos a essa população. Portanto, torna-se evidente a necessidade de pesquisas voltadas para a comunidade 
transgênero, ressaltando as barreiras e dificuldades impostas a ela na inserção no mercado de trabalho.

Logo, esta pesquisa teve como objetivo analisar a percepção de barreiras e de planejamento de carreira de mulheres transexuais e travestis, avaliando a importância desse processo para estas mulheres. Esperamos, ao identificar as principais barreiras encontradas por elas no mercado de trabalho, propor estratégias e maneiras efetivas de transpô-las. Além disso, ao analisar o processo de planejamento, espera-se contribuir para a revisão das categorias habituais de carreira impostas a elas devido à baixa capacitação e preconceitos por sua identidade de gênero, como a prostituição $e$ outras profissões precarizadas (Teixeira, 2008; Martendal, 2015; Figueiredo, 2017).

\section{Carreira de mulheres transexuais e travestis}

Identidade de gênero, de acordo com Associação Nacional de Travestis e Transexuais (ANTRA, 2018:1), "é a forma como o indivíduo se vê, é reconhecido e se reconhece na sociedade a partir da dicotomia Homem x Mulher". Entretanto, destaca-se que discussões sobre as distinções entre sexo, gênero e sexualidade têm extrapolado tal dicotomia por considerá-la binária. Ao abordar o sujeito abjeto, Butler (2003) lança luz àqueles que não se enquadram nas categorias conhecidas e que não seguem a lógica dos "gêneros inteligíveis". Nessa lógica, que ainda vigora atualmente, predominam referências ditas heteronormativas, segundo as quais quem tem pênis é homem, masculino e sente atração afetivo-sexual por mulheres, assim como quem tem vagina é mulher, feminina e sente atração afetivo-sexual por homens. Nesse sentido, pessoas homossexuais, bissexuais, intersexuais, travestis, transexuais e todas aquelas que rompem com tais padrões seriam consideradas abjetas (Butler, 2003).

Concernente à descrição de mulheres transexuais e travestis, a Associação Nacional de Travestis e Transexuais (ANTRA) elucida:

Mulheres Transexuais - Pessoas que foram designadas enquanto homens no nascimento, mas que se reconhecem enquanto mulheres. Admitindo uma identidade de gênero diferente da que foi imposta e fazendo readequações que julgam necessárias para vivenciar de forma confortável o gênero que se identificam/pertencem (readequações, cirurgias ou modificações corporais não são marcadores determinantes da identidade gênero e tão pouco são uma regra). Travestis Pessoas que foram designadas enquanto homem no nascimento, mas que se reconhecem enquanto pertencentes ao gênero feminino, mas que não reivindicam a identidade de 'Mulher' (Cartilha Gênero - ANTRA:2).

Faz-se necessário ressaltar, contudo, que as definições de transexuais e travestis também tem ido além das questões de identidade associadas às categorias "homem" e "mulher", muitas vezes se mostrando como difusas e intercaláveis entre as próprias pessoas que as assumem, conforme apontado por Barbosa (2013). Em seu estudo, Barbosa (2013) evidencia uma variedade de reelaborações e deslocamentos de sentidos, argumentando que travesti e transexual seriam categorias performativas que não se esgotam em termos de gênero e sexualidade, sendo expressas por diferenças de classe, cor/raça e geração.

Consideradas transgressoras pela sociedade, travestis e transexuais enfrentam diversas barreiras em ambientes distintos, dentre eles a escola, unidades do serviço público de saúde e mercado de trabalho formal. $\mathrm{O}$ trabalho, além de garantir os recursos materiais para suprir as necessidades básicas do homem, configura um fator de identificação fundamental na determinação da inserção do indivíduo na sociedade em que habita (Segnini, 2000). Para aumentar as chances de inclusão no mercado de trabalho a longo prazo, o indivíduo deveria, em tese, se responsabilizar pelo seu autodesenvolvimento, o que incluiria estratégias de transformação pessoal e profissional, caberia a ele buscar o desenvolvimento de suas habilidades e competências para lhe garantir vantagem competitiva e maiores oportunidades de trabalho (Malschitzky, 2012).

A escola tem papel essencial nesse processo, visto que se volta para a preparação $e$ formação profissional considerando as demandas do mercado de trabalho. Isto é, o nível de escolaridade tem grande influência sobre o acesso às oportunidades e a inserção mais ou menos precária no mercado 
de trabalho (Segnini, 2000). A partir disto, faz-se necessário refletir acerca das barreiras sociais enfrentadas por mulheres transexuais e travestis ao longo de seu desenvolvimento profissional.

As primeiras barreiras irrompem, em muitos casos, no âmbito familiar. Estima-se que a média de idade em que travestis e transexuais são expulsas de casa pelos pais é de 13 anos (ANTRA, 2018). Discriminadas e marginalizadas, saem de casa ainda jovens em busca de apoio, mas encontram dificuldades no acesso aos seus direitos, como educação, segurança, saúde e trabalho. Em vista disso, observa-se uma recorrente evasão escolar ocasionada pelas hostilidades sofridas na vivência acadêmica, o que influencia diretamente, de forma negativa, as possibilidades de inserção no mercado formal de trabalho devido à baixa capacitação, somada ao preconceito pela sua identidade de gênero (Souza; Costa; Rodrigues, 2016).

A falta de capacitação profissional dessa população reforça as barreiras encontradas no mercado de trabalho. É dificultada a inserção em empregos fora das categorias habituais de atividade profissional em que são aceitas, como por exemplo, as indústrias do sexo e da estética (Teixeira, 2008; Figueiredo, 2017). A busca por emprego depois de iniciada a transição é também dificultada pela discriminação e desconhecimento em relação ao que significa ser transexual. Devido à baixa escolaridade e os preconceitos velados de muitas empresas contra mulheres transexuais e travestis, as portas do mercado formal de trabalho se fecham $e$ as opções mais comumente encontradas para sua atuação são a de trabalhadora sexual, cabeleireiras $e$ depiladoras, além das ocupações nos setores da moda e alimentos, como costureiras e cozinheiras (Martendal, 2015; Kaffer et al., 2016). Isso corrobora com os estudos da Associação Nacional das Travestis e Transexuais (ANTRA) realizados em 2015, os quais indicam que $90 \%$ dessas mulheres estão se prostituindo em todo o Brasil, e as que não se encontram nessa situação trabalham em profissões subalternas, ganhando baixos salários (Martendal, 2015; Dias; Bernardineli, 2016).

Em pesquisa realizada por Rondas e Machado (2015), transexuais e travestis apontaram o ambiente de trabalho como o que apresenta maior dificuldade para sua aceitação enquanto cidadãs. Foram identificados obstáculos como hostilidade, aversão, intolerância, chacota, preconceito, assédio sexual, impossibilidade de promoção e de se destacar no ambiente de trabalho, baixa remuneração, acúmulo de funções, baixa valorização, trabalho exaustivo $e$ estressante. Budge, Tebbe e Howard (2010), por sua vez, pontuam que tais dificuldades podem ser consequência da falta de conhecimento das organizações e colegas de trabalho, acerca de quais transformações são necessárias para propiciar um ambiente de trabalho resguardado e livre de discriminação para transgêneros. A manutenção de concepções equivocadas pode gerar receios à organização e seus colaboradores, resultando no isolamento dessas pessoas, diminuindo as oportunidades de socialização e colaboração em projetos e ocasionando baixo desempenho (Brown et al., 2012; Pedreira; Santos, 2018).

Além disso, questões cotidianas tornam-se alvos de reclamações, hostilidade ou outras consequências negativas, como por exemplo, o uso do banheiro - uma ação despretensiosa que se transforma em um dilema - e o uso do nome social, que apesar de ser regulamentado em nível federal pelo Decreto $n^{\circ} 8727 / 2016$, tem aplicação restrita ao âmbito da administração pública federal direta, autárquica e fundacional. Logo, tal recurso ainda sofre violação e discriminação, talvez em função de não ser respaldado por lei federal e, portanto, não ter validade em território nacional para outros órgãos/entes, exceto aqueles indicados no decreto. A antecipação dessas discriminações, aliada à conscientização de que existem poucos recursos legais, costuma provocar aumento de estresse em transexuais (O'Neil; Mcwhirter; Cerezo, 2008; Chope; Strom, 2008; Dias; Bernardineli, 2016; Pedreira; Santos, 2018).

No que diz respeito ao processo de transição, quando ocorre ao longo do vínculo com uma organização ou empregador, não é incomum que seja acompanhado de retaliações e até mesmo demissões (Almeida; Vasconcellos, 2018). Na pesquisa de Schilt \& Connell (2007) sobre transição de gênero no local de trabalho, participantes frequentemente relataram experiências de sexismo no ambiente laboral. Após a transição de gênero, homens e mulheres trans enfrentaram situações nas quais havia determinadas expectativas e ideologias de gênero. Homens transexuais eram alistados a rituais masculinos, como por exemplo, o deslocamento de caixas pesadas para outros locais, e mulheres transexuais eram convidadas a participarem de conversas sobre maquiagens e roupas. 
Embora os entrevistados tenham interpretado essas ações como uma validação social, numa tentativa dos seus colegas de demonstrar aceitação, tal situação entra em conflito com suas habilidades físicas e interesses pessoais, bem como com suas próprias concepções de gênero. Outra expressão de sexismo se deu com os trabalhadores que, ao se tornarem mulheres transexuais, perderam suas posições em altos cargos e promoções, pois eram vistas como inadequadas ao cargo, enquanto trabalhadores que se tornaram homens transexuais passaram a ser mais valorizados do que o eram como mulheres (Schilt; Connell, 2007).

Ao analisar estudos referentes à inserção das mulheres transexuais e travestis no mercado de trabalho, corroboram-se as asserções das pesquisas relativas à carreira. É possível identificar resultados análogos e semelhantes a achados anteriores nos estudos de Teixeira (2008), Rondas e Machado (2015), Martendal (2015) e Figueiredo (2017), segundo os quais as barreiras enfrentadas por pessoas transexuais para inserção no mercado formal de trabalho são: a falta de acesso à qualificação; a condição de identidade que por vezes é patologizada; o preconceito e a transfobia; documentos, tais como registro civil e certificado de reservista; uso de banheiro, vestiário e uniforme; baixa escolaridade e evasão escolar involuntária (Carvalho, 2006; Dias; Bernardineli, 2016; Almeida; Vasconcellos, 2018).

Portanto, ressalta-se que o enfrentamento dos diversos modos de discriminação pela população transgênero incide diretamente em suas escolhas de carreira e metas profissionais. Lent, Brown e Hackett (2000) pontuam que influências contextuais negativas, como a discriminação, diminuiriam os interesses de carreira em ocupações em que o risco percebido por ser um alvo da heteronormatividade fosse alto. Similarmente, Brown et al. (2012) apresentaram dados que sugerem que locais de trabalho percebidos como mais tolerantes e seguros são alvos de maior interesse, dentre os quais estão as carreiras em educação e profissões predominantemente femininas. Porém, é necessário ressaltar que carreiras profissionais deveriam ser escolhidas com base nos interesses em determinados campos de estudo e conhecimento, assim como na compatibilidade entre eles e áreas que permitam a expressão de suas personalidades. Logo, a busca pela educação, treinamento e capacitação para a carreira e segurança financeira após a transição de gênero são metas estabelecidas com alta prioridade pela população transexual, o que aponta para a importância do planejamento de carreira (Adams; Cahill; Ackerlind, 2005; Brown et al., 2012).

\section{Planejamento de carreira}

O planejamento de carreira se trata de um construto complexo que dialoga com vários outros conceitos relacionados com o desenvolvimento profissional, tais como a percepção de autoeficácia, percepção de barreiras na carreira, suporte na carreira e realização profissional (Ourique, 2010). Ao planejar sua carreira, o indivíduo deve procurar conhecer mais acerca de si mesmo e se aventurar na busca de atividades exploratórias, para que possa descobrir novas informações sobre o mundo de trabalho. O processo de planejar a carreira acontece ao longo de toda a vida, de forma que os esforços despendidos podem ser mais ou menos intensos em diferentes momentos da carreira (Ourique, 2010).

Um fator importante no planejamento de carreira é a autoeficácia, que diz respeito à confiança na capacidade pessoal para organizar e executar certas ações (Bandura, 1997). A autoeficácia relaciona-se as preferências ocupacionais, perspectiva de resultados, características comportamentais, metas de carreira e desfechos alcançados no âmbito da escolha profissional (Lent; Brown; Hackett, 1994). Outro fator relevante para o planejamento de carreira é o apoio social, que se refere à rede de familiares e amigos que aconselham, dão assistência e encorajam os sujeitos em suas decisões. Conforme Slebarska e colaboradores (2009), o apoio social tem se revelado um dos fatores mais importantes entre os preditores situacionais da busca de emprego. Em suma, as escolhas de caráter profissional se relacionam diretamente ao processo de formação dos interesses de carreira, estando submetidas às influências do contexto e do ambiente em que os sujeitos estão inseridos, além de perpassar fatores pessoais, políticos, sociais, econômicos, familiares e culturais (Lent; Brown; Hackett, 1994).

Por outro lado, a percepção de barreiras na carreira pode afetar consideravelmente a percepção de autoeficácia, o que acabaria por influenciar o processo de planejamento de carreira. 
Barreiras na carreira são "acontecimentos ou condições, no interior do sujeito ou no seu ambiente, que lhe tornam difícil progredir na carreira" (Swanson; Woitke, 1997:446). São passíveis de superação, apesar de possuírem níveis diversos de complexidade em função de suas propriedades $e$ características específicas.

Crites (1969) faz distinção entre barreiras internas e externas, pontuando que as barreiras consideradas internas podem ser entendidas como falta de confiança ou baixa motivação, enquanto exemplos das externas seriam a pobreza e falta de acesso à educação. A falta de confiança $e$ a dificuldade de tomar uma decisão poderiam ser consideradas barreiras relacionadas a fatores internos (Swanson; Woitke,1997). Discriminação sexual, desencorajamento para escolher uma carreira menos tradicional e preocupações com a saúde, por sua vez, podem ser consideradas barreiras externas, relacionadas às influências contextuais. Desse modo, a percepção de barreiras na carreira é influenciada por fatores multidimensionais, dentre os quais estão autoconhecimento, aptidões profissionais, interesses, características demográficas (sexo e idade), família, casamento, filhos e pessoas significativas (Swanson; Tokar, 1991).

No tocante à importância do planejamento de carreira, em específico, para mulheres transexuais e travestis, nenhum estudo empírico foi encontrado na literatura até o momento. Esta foi a constatação de uma breve pesquisa realizada no Google Acadêmico, SciELO e Portal de Periódicos CAPES com as palavras-chave transexualidade e carreira, mulheres trans e carreira, planejamento de carreira e transexuais. Os mesmos termos foram pesquisados na língua inglesa $e$ obtiveram resultados análogos. No Brasil, observou-se apenas a existência de estudos relativos às dificuldades da comunidade transgênero de inserção no mercado formal de trabalho. A nível internacional, as pesquisas estrangeiras diziam respeito às experiências de trabalho dos indivíduos transgêneros, as barreiras enfrentadas no mercado de trabalho e orientações para o aconselhamento de carreira com clientes transexuais, não havendo, porém, estudos que tratassem, especificamente, do processo de planejamento de carreira. O estudo mais proximal encontrado foi o de Adams, Cahill \& Ackerlind (2005), que pesquisaram o processo de desenvolvimento de carreira de jovens gays e lésbicas. Foi constatado que o planejamento para o alcance de metas era extremamente vago, mas que consideravam importante o apoio de familiares $e$ amigos nesse processo.

Perante a situação de fragilidade do processo de empregabilidade e as barreiras encontradas para se inserir no mercado, faz-se importante pensar a noção de um planejamento de carreira para que esse público possa elaborar objetivos de carreira claros e saiba qual trajetória profissional seguir. Assim, fazem-se necessárias pesquisas na área de carreira que investiguem as barreiras enfrentadas por essa população. Dada a grande incidência dessas mulheres em atividades de risco, como a prostituição, e em profissões subalternas ganhando baixos salários, esse estudo teve como objetivo investigar a inserção profissional, percepção de barreiras e planejamento de carreira de mulheres transexuais e travestis.

\section{Método}

\section{Amostra}

Composta por cinco mulheres, três que se identificavam com o termo transexual e duas com o termo travesti, solteiras, na faixa etária de 20-35 anos, que passaram ou ainda passam pelo processo de transição. Dentre as entrevistadas, uma concluiu o ensino fundamental, duas cursavam o ensino superior e duas já o haviam concluído. Quatro residiam no estado de Minas Gerais e uma no estado de São Paulo. Todas já estavam inseridas no mercado de trabalho, havendo um histórico de diversas atuações profissionais que serão apresentadas nos resultados e discussão. Ressalta-se que procurou-se evitar que a maior parte das participantes apresentasse atuações de trabalho estereotipadas ou associadas à indústria do sexo e da beleza. Isto se justifica pelo fato de que se considera que qualquer trabalho pode ser exercido pelas mesmas, e não apenas aqueles que lhes são mais comumente associados. 


\section{Instrumento}

Foi utilizado um roteiro de entrevista semiestruturado, que conforme disposto na Tabela 1 abordou as temáticas de transição de gênero e experiências pregressas (Bloco 1), percepção de barreiras na carreira (Bloco 2) e planejamento de carreira (Bloco 3). O primeiro bloco de questões justifica-se pela especificidade do público pesquisado visto que, enquanto transexuais, realizam transformações visuais a fim de se adequarem ao gênero o qual se identificam e essas podem interferir em suas oportunidades profissionais, conforme apontado por Almeida e Vasconcellos (2018). O segundo e terceiro blocos dizem respeito ao objetivo de pesquisa.

\section{Tabela 1 - Roteiro de entrevista}

\section{BLOCO 1}

Quando você se identificou como uma mulher? Quando realizou a transição visual?

\section{BLOCO 2}

Qual profissão você exerce atualmente? Essa profissão está condizente com o que você gostaria de fazer em termos de carreira?

\begin{tabular}{|c|c|c|}
\hline $\begin{array}{l}\text { Quais foram suas experiências no } \\
\text { mercado de trabalho antes da } \\
\text { mudança de gênero? }\end{array}$ & $\begin{array}{l}\text { Quais as principais barreiras que } \\
\text { você enfrenta no momento para } \\
\text { trabalhar na área que deseja? }\end{array}$ & $\begin{array}{l}\text { Você realiza algum tipo de } \\
\text { planejamento ou organização } \\
\text { (cursos, educação) em relação ao } \\
\text { que você deseja alcançar } \\
\text { profissionalmente? Se sim, o quê?? } \\
\text { Se não, por quê? }\end{array}$ \\
\hline
\end{tabular}

Você percebia alguma barreira De que maneira você associa as Você recebeu algum tipo de para pensar em ou construir sua barreiras que você enfrenta à sua carreira antes da transição? Se sim, identidade de gênero? Você quais? percebe haver alguma relação? Dê suporte para planejar sua carreira? (Família, amigos, ONGs, Estado) exemplos.

Você recebeu algum tipo de Quais as principais barreiras que suporte para a transição? Qual? identifica para alcançar seus futuros objetivos profissionais?

\section{BLOCO 3}

Qual a sua opinião sobre planejamento de carreira? Se não, por quê?

\section{Procedimentos e análise de dados}

Esta pesquisa foi submetida ao Comitê de Ética em Pesquisa com Seres Humanos - CEP da Universidade Federal de Uberlândia - UFU e, após a emissão de parecer consubstanciado de aprovação número 2.826 .849 de $16 / 08 / 2018$, a equipe de pesquisa iniciou o processo de recrutamento das participantes. O recrutamento sucedeu-se de maneiras diversas: três entrevistadas foram recrutadas em um evento científico direcionado ao público trans. Uma participante foi recrutada por meio de uma rede social, através da página de divulgação da parada LGBT. Por fim, uma entrevistada foi recrutada numa roda de conversa sobre o Dia da Mulher. Todas receberam esclarecimentos sobre os parâmetros éticos e os objetivos da pesquisa, e concordaram em participar após apresentação e assinatura do Termo de Compromisso Livre e Esclarecido (TCLE).

Os dados foram analisados por meio da análise de conteúdo, que segundo Bardin (2009) é um método de análise de texto desenvolvido dentro das ciências sociais empíricas e que permite produzir de maneira objetivada inferências de um texto focal para seu contexto social. Muitas vezes, implica em um tratamento estatístico das unidades de texto, podendo utilizar como base a frequência de termos (descrições numéricas) ou categorias temáticas (codificar em classes de equivalência definidas). 
A análise de conteúdo foi realizada através do software QDA Miner, direcionado para análise qualitativa de dados. Nesse programa, foi efetuada a categorização temática das entrevistas, relacionando o seu conteúdo com informações estruturadas, tais como dados numéricos $e$ categóricos. O QDA Miner favorece o gerenciamento, a codificação e análise de dados qualitativos, uma vez que permite a leitura dos textos por entrevistado ou por pergunta; o desenvolvimento de um esquema de codificação manual ou usando ferramentas de frequência de palavras; a pesquisa de texto e a autocodificação; a codificação envolvendo indexação versus redução de dados; verificação de códigos observando a consistência e a omissão; busca por semelhanças ou diferenças (Nunes et al., 2017).

\section{Resultados e Discussão}

Devido à especificidade da amostra deste estudo, investigamos com as questões do Bloco 1 aspectos relativos à transição de gênero, uma vez que esses desempenhariam nas participantes importante influência sobre as decisões de carreira, além de contribuírem para proporcionar uma compreensão ampliada dos dados. Questionamos às entrevistadas quando se reconheceram enquanto mulheres, quando começaram a transição de gênero e se para tal receberam algum suporte.

Para Chowdhury e Gibson (2019), a identificação com o gênero oposto ocorreria ainda na primeira infância, o que foi também verificado no discurso da amostra. Três entrevistadas disseram ter se reconhecido como do gênero oposto de seu nascimento ainda na infância, desde as primeiras brincadeiras, e duas afirmaram que se percebiam diferentes, mas que esse reconhecimento se deu recentemente, já na fase adulta. Com relação àquelas que se reconheceram na infância, o começo da transição ocorreu entre 15 e 18 anos de idade, com a utilização de hormônios após essa faixa etária. Aquelas que se reconhecerem recentemente consideram que ainda estão passando pelo processo de transição.

"Desde sempre eu me identificava enquanto mulher, desde criança" (Entrevistada 2)

"Tem mais ou menos dois anos que eu me reconheci mesmo (...) ainda estou, sempre digo que estou em transição porque a gente nunca para, a gente nunca é, a gente está sendo"” (Entrevistada 1)

"A minha transição eu comecei acho que com 14 para 15 anos, e a tomar hormônio que é uma coisa mais profunda foi com 17 para 18 anos" (Entrevistada 5)

Concernente ao suporte recebido para transição, quatro entrevistadas citaram o importante apoio do Centro de Referência Atenção Integral à Saúde Transespecífica (CRAIST) do Hospital de Clínicas da Universidade Federal local, que oferece serviços multidisciplinares em saúde e assistência social. Também mencionaram os amigos mais próximos como parte desse suporte, excluindo-se os familiares. Em seu estudo, Pedreira e Santos (2018), constataram que o respeito da família é um fator preponderante para amenizar as dificuldades encontradas durante a transição, dado que a ausência desse suporte somado à instabilidade financeira direciona o indivíduo a trabalhos subalternizados e marginalizados. Sendo assim, a ausência do suporte familiar pode representar um dificultador para a inserção em profissões não marginalizadas.

Para análise e discussão dos demais dados, na Tabela 2 estão dispostas as quatro categorias de análise, que foram criadas baseadas nas questões do roteiro de entrevista. Posteriormente, são apresentados os principais resultados a partir dos temas identificados na análise de conteúdo das entrevistas. 
Tabela 2 - Categorias de análise

\begin{tabular}{|c|c|c|}
\hline CATEGORIA & DEFINIÇÃO & PERGUNTAS \\
\hline Trajetória de Carreira & $\begin{array}{l}\text { Busca investigar as experiências no } \\
\text { mercado de trabalho antes e após a } \\
\text { transição de gênero }\end{array}$ & $\begin{array}{l}\text { - Quais foram suas experiências no } \\
\text { mercado de trabalho antes da mudança } \\
\text { de gênero? } \\
\text { - Qual profissão você exerce } \\
\text { atualmente? Esta profissão está } \\
\text { condizente com o que você gostaria de } \\
\text { fazer em termos de carreira? }\end{array}$ \\
\hline Barreiras na carreira & $\begin{array}{l}\text { Busca investigar a percepção de } \\
\text { barreiras na carreira antes e após a } \\
\text { transição }\end{array}$ & $\begin{array}{l}\text { - Você percebia alguma barreira para } \\
\text { pensar em ou construir sua carreira } \\
\text { antes da transição? Se sim, quais? } \\
\text { - Quais as principais barreiras que você } \\
\text { enfrenta no momento para trabalhar na } \\
\text { área que deseja? } \\
\text { - De que maneira você associa as } \\
\text { barreiras que você enfrenta à sua } \\
\text { identidade de gênero? Você percebe } \\
\text { haver alguma relação? Dê exemplos. } \\
\text { - Quais as principais barreiras que } \\
\text { identifica para alcançar seus futuros } \\
\text { objetivos profissionais? }\end{array}$ \\
\hline Planejamento de carreira & $\begin{array}{l}\text { Busca investigar a importância do } \\
\text { planejamento de carreira e se ele é } \\
\text { realizado }\end{array}$ & $\begin{array}{l}\text { - Qual a sua opinião sobre planejamento } \\
\text { de carreira? } \\
\text { - Você realiza algum tipo de } \\
\text { planejamento ou organização (cursos, } \\
\text { educação) em relação ao que você } \\
\text { deseja alcançar profissionalmente? Se } \\
\text { sim, o quê? Se não, por quê?? }\end{array}$ \\
\hline Suporte na carreira & $\begin{array}{l}\text { Busca investigar se há o suporte para o } \\
\text { planejamento de carreira }\end{array}$ & $\begin{array}{l}\text { - Você recebeu algum tipo de suporte } \\
\text { para planejar sua carreira? (Família, } \\
\text { amigos, ONGs, Estado) } \\
\text { - Que tipo de ajuda ou suporte você } \\
\text { acredita que poderia receber para ajudar } \\
\text { a planejar sua carreira? }\end{array}$ \\
\hline
\end{tabular}

\section{Trajetórias de carreira}

Buscando compreender a trajetória de carreiras dessas mulheres, investigou-se em quais áreas atuaram profissionalmente antes e após a transição de gênero. Nas áreas anteriores à transição, foi comum a presença do ramo alimentício, o que na amostra em questão incluiu locais como casa de carnes, sorveteria, lanchonete, restaurante e fast food. As demais atuações foram em ramos diversos, abrangendo Câmara Municipal, menor aprendiz e lojas de comércio e varejo.

Observa-se que estas experiências profissionais se deram a partir de oportunidades que surgiram, não estando diretamente relacionadas às escolhas de carreira. $\mathrm{Na}$ época destas experiências, as participantes frequentemente apontaram ser menores de idade com formação escolar básica, o que reforça a premissa de que o nível de escolaridade tem grande influência sobre o acesso às oportunidades e à precariedade da inserção no mercado de trabalho (Segnini, 2000). Com relação às áreas de atuação posteriores à transição de gênero, três entrevistadas tiveram inserções em diversos âmbitos do mercado de trabalho, tais como caixa de supermercado, auxiliar de serviços gerais, auxiliar de limpeza, prostituição e salão de beleza. Tal realidade é compatível com aquela apontada por Martendal (2015), segundo a qual $90 \%$ das mulheres transexuais e travestis estão se prostituindo em todo o Brasil, $e$ as que não se encontram nessa situação trabalham em profissões subalternas ganhando baixos salários.

Com relação às ocupações atuais, duas participantes são estudantes do ensino superior nos cursos de graduação em pedagogia e serviço social, uma atua como psicóloga clínica e assessora parlamentar, outra é proprietária de lanchonete e jornalista freelancer, e a última é auxiliar de limpeza. De acordo com a teoria de Super, Savickas e Super (1996), as que são estudantes estariam 
no estágio de exploração, visto que transformaram suas preferências gerais em específicas, escolheram uma profissão e estão colocando os objetivos de formação profissional em prática. A auxiliar de limpeza também estaria no estágio de exploração, visto que demonstrou em sua fala que tomou algumas decisões relacionadas a programas educacionais, buscando alcançar seus objetivos. A psicóloga e a jornalista estariam no estágio de estabelecimento, pois demonstraram estar buscando a segurança e consolidação na área de atuação escolhida.

A despeito de duas entrevistadas possuírem o ensino superior e duas estarem em formação, todas relataram ter encontrado dificuldades para atuar nas carreiras escolhidas, sendo eventualmente forçadas a buscarem inserção em funções precarizadas, a fim de garantir sua subsistência. Tal cenário é compatível com as previsões da literatura, que indicam que a evasão escolar ocasionada por hostilidades sofridas no período acadêmico influi negativamente sobre as possibilidades de inserção no mercado formal de trabalho, dificultando a atuação em empregos fora das categorias habituais (Teixeira, 2008; Martendal, 2015; Souza; Costa; Rodrigues, 2016; Figueiredo, 2017). Questionadas se a profissão atual estava condizente com o que gostariam de fazer em termos de carreira, quatro entrevistadas consideraram que não.

"Depois de um tempo, quase dois anos fazendo um curso eu percebi que não é esse o curso que eu quero" (Entrevistada 1)

"Não é o que eu queria, mas está quebrando um galho"(Entrevistada 4)

A partir desse descontentamento com a atuação profissional, mesmo não sendo diretamente questionadas sobre isto, todas as entrevistadas relataram o estabelecimento de metas para alcançarem seus futuros objetivos de carreira. Dentre esses, quatro envolviam a busca por capacitação, desde a conclusão do ensino médio, cursos profissionalizantes, até pós-graduação; três estabeleciam planos claros para atuação e crescimento na área de formação; dois implicavam na mudança de carreira no futuro próximo. Como identificado em outros estudos, a busca pela educação, treinamento e capacitação para a carreira na pós-transição de gênero são metas estabelecidas com alta prioridade pela população transexual (Adams; Cahill; Ackerlind, 2005; Brown et al., 2012).

"Montar meu atelier. Fazer cursos de cabelo, maquiagem, depilação" (Entrevistada 4)

"Entrar no mestrado, doutorado e também ir pra sala de aula" (Entrevistada 2)

"Ter uma grande representatividade nacional com o meu trabalho no jornalismo" (Entrevistada 5)

"Estudar para ser uma cientista social" (Entrevistada 1)

Lent, Brown e Hackett (2000) e Brown et al. (2012) sugerem que locais de trabalho percebidos como mais tolerantes e seguros são alvos de maior interesse, incluindo carreiras em educação e profissões predominantemente femininas. Nota-se que as escolhas de carreira das entrevistadas enquadram-se nessas categorias, visto que duas objetivam atuar em educação, uma em saúde e outra na área de estética. Apenas uma foge à norma atuando no jornalismo, considerada uma profissão ora neutra ora predominantemente masculina (a depender da área de especialização). Apesar disso, todas alegaram sofrer discriminações e enfrentar diversas barreiras na carreira.

\section{Barreiras na carreira}

Segundo Swanson e Woitke (1997), barreiras na carreira dizem respeito às condições internas ou externas ao indivíduo e que dificultam o progresso em sua carreira. Barreiras externas referem-se às influências contextuais, enquanto as internas apontam questões relativas à falta de confiança $e$ dificuldades para tomada de decisão (Crites, 1969; Swanson; Woitke, 1997). Visando abarcar os diversos modos como elas se apresentam, questionamos as entrevistadas acerca da percepção de barreiras na carreira anteriores à transição, barreiras que enfrentam para atuar na área em que desejam, barreiras ligadas diretamente à sua escolha de gênero e barreiras para alcançarem seus 
futuros objetivos profissionais. Abaixo destacamos as principais barreiras elencadas pelas entrevistadas:

\section{Transfobia}

Unanimemente, as participantes elegeram a transfobia como a principal barreira para o desenvolvimento de suas carreiras. Esta corresponde a concepções reducionistas, negativas e ações discriminatórias contra transexuais e travestis, destacando-se as falas:

"Falaram que não me contratariam por terem pais que não aceitariam uma mulher transexual como professora" (Entrevistada 2)

"Já me disseram: olha enquanto você estiver fazendo entrevista vestido desse jeito, você não vai arrumar serviço" (Entrevistada 4)

"Quando eles leem o papel, chamam e tem interesse, mas a hora que você tem uma entrevista de emprego eles olham para minha cara e se dão conta que se trata de uma travesti, negam o emprego" (Entrevistada 5)

As entrevistadas apontaram que, desde a entrega do currículo até a contratação, encontram dificuldades e passam por discriminações. Isto é reforçado por Dias e Bernardineli (2016) em seu estudo, que aponta que a eliminação da possível candidatura transexual à vaga ocorre devido a sua aparência ou discrepância entre nome e aparência física. Em suma, estas discriminações se apresentam de diversos modos, como apontado pelas entrevistadas, em dificuldades com o uso do nome social, padrão estético, estigma social e assédio sexual. Em primeiro lugar, apontada por quatro das participantes, as resistências encontradas no reconhecimento do nome social vão desde a entrega do currículo até a identificação e tratamento dentro da organização. A segunda dificuldade, mencionada por duas das entrevistadas, trata-se dos padrões de beleza instituídos pela sociedade, que determinam qual aparência física é aceitável, influindo sobre os diversos modos de relacionamento e oportunidades de emprego. A terceira, o estigma social, entendido como uma desaprovação de características ou crenças pessoais que vão contra as normas culturais e levam à desagregação social, foi apontada por duas das mulheres. Segundo elas, o estigma da mulher transexual e travesti gera complicações nos locais de trabalho, em geral desencadeando assédio sexual.

Citado por uma das participantes, o assédio sexual refere-se à coerção sexual praticada comumente por uma pessoa em posição hierárquica superior em relação a um subordinado. Tais resultados também foram encontrados em estudos anteriores, que destacam como dificultadores da inserção profissional de trans e travestis o papel do preconceito, da transfobia, das complicações com registro civil e uso do nome social, da intolerância e do assédio sexual (Carvalho, 2006; O'Neil; Mcwhirther; Cerezo, 2008; Chope; Strom, 2008; Rondas; Machado, 2015; Dias; Bernardineli, 2016; Almeida; Vasconcellos, 2018). As falas seguintes evidenciam o exposto:

"O mercado gosta de rotular muito nós que somos trans, quanto mais bela, mais perfeita você for, mais você é apta para o mercado de trabalho" (Entrevistada 4)

"No mercado que trabalhei, foi o estigma da mulher trans como prostituta. O segurança de lá, o açougueiro também, uma vez quis tentar me agarrar. Ele chegava pra conversar comigo e era sempre sobre sexo" (Entrevistada 3)

\section{Homofobia}

Percebida por quatro das participantes, ocorreu anteriormente à transição de gênero, pois as entrevistadas relataram apresentar características comumente associadas a pessoas homossexuais. Por outro lado, duas afirmaram que apesar de demonstrarem tais características, não as consideraram uma barreira.

"Preconceitos porque no caso ainda era outra performance" (Entrevistada 1) 
"Às vezes a gente pensava: não vai nem me contratar por causa de eu ser gay" (Entrevistada 4)

"Ainda as pessoas me liam visualmente como apenas uma gay afeminada. Não me reconheciam e não me intitulavam como uma figura travesti. Até então não tinha problema com emprego."

(Entrevistada 5)

\section{Dificuldades financeiras e falta de oportunidades}

Identificadas como barreiras externas que enfrentam para atuarem nas áreas que desejam $e$ para alcançarem seus futuros objetivos profissionais, conforme proposto por Swanson e Woitke (1997), quatro das entrevistadas nomearam ora barreiras financeiras, isto é, carência de recursos para suprirem suas necessidades básicas, ora falta de oportunidades, como dificuldades para inserção no mercado de trabalho ou financiamento de cursos de formação. Destacaram, principalmente, como a situação financeira poderia impedir que seus planos se concretizassem no tempo determinado, e como a falta de oportunidades ocasionada pelo preconceito poderia dificultar sua inserção nas áreas de carreira escolhidas. Uma das entrevistadas identificou como sua principal barreira a falta de formação.

As falas descritas a seguir corroboram com os estudos que identificaram as diversas barreiras para transexuais se inserirem no mercado formal de trabalho, destacando-se a falta de acesso à qualificação (Carvalho, 2006; Dias; Bernardineli, 2016; Almeida; Vasconcellos, 2018).

\footnotetext{
"Eu tive que entrar na vida de prostituição e não foi porque eu quis, foi por necessidade. Eu precisava de dinheiro. Eu queria fazer curso para me qualificar mais, não consigo, curso pela prefeitura travesti não consegue" (Entrevistada 4)

"O meu maior desejo sempre foi trabalhar como jornalista, mas depois que eu saí da faculdade percebi que as pessoas não iriam me contratar (...) a minha principal dificuldade ainda é as pessoas não me reconhecerem como uma profissional" (Entrevistada 5)

"Eu acredito que a falta de dinheiro" (Entrevistada 1)

"Porque depende muito da condição financeira, depende muito de como eu vou estar lá" (Entrevistada 2)
}

Percebe-se que a questão da formação representa um ciclo vicioso que sustenta a permanência dessas pessoas à margem da sociedade. As discriminações sofridas durante a formação impulsionam a evasão escolar, que por sua vez dificulta a inserção $e$ a ascensão no mercado formal de trabalho por falta de qualificação. O desemprego gera condições precárias de sobrevivência, que impossibilitam o investimento em cursos de formação e nutrem negativamente questões ligadas ao autoconceito. Em suma, as dificuldades para o apropriado desenvolvimento profissional e de carreira contribuem para que as mulheres transexuais e travestis permaneçam à margem da sociedade, sem perspectiva de ascensão social.

Portanto, apesar de quatro das entrevistadas possuírem certa qualificação profissional (duas graduandas e duas com formação superior concluída), todas perceberam barreiras relativas à inserção e alcance dos futuros objetivos profissionais. Assim, evidencia-se a existência de barreiras externas intimamente ligadas à transição de gênero, que impedem ou dificultam a colocação digna dessas mulheres no mercado formal de trabalho a partir de suas próprias escolhas de carreira. Desta forma, compreende-se que "escolher" seria algo socialmente negado a estas mulheres, o que reforçaria sua inserção profissional em áreas precarizadas ou na prostituição.

\section{Barreiras no cotidiano}

A população transexual enfrenta múltiplos obstáculos em virtude de sua condição de vulnerabilidade social. Alguns deles são barreiras que se impõem diretamente ao seu desenvolvimento profissional, que se manifestam em contextos distintos ao da carreira, mas que podem vir a influenciar indiretamente a mesma. As participantes relataram situações de transfobia que também vivenciaram em meio aos familiares, em locais públicos, e em interações com oficiais 
da lei. Além disso, tem-se a complexidade para acesso a hormônios e acompanhamento médico durante a transição, assim como as dificuldades no uso do banheiro.

As falas que se seguem corroboram com os estudos que apontaram aspectos como o uso do banheiro, do nome social, a condição de identidade que por vezes é patologizada, a dificuldade para retificação de registros civis, o preconceito e a transfobia como barreiras enfrentadas pela população transexual em situações tanto cotidianas quanto de trabalho (Carvalho, 2006; O'Neil; Mcwhirter; Cerezo, 2008; Chope; Strom, 2008; Dias; Bernardineli, 2016; Almeida; Vasconcellos, 2018). Tais aspectos se mostram relevantes porque refletem a complexidade da vivência trans $e$ travesti, indicando o quão primárias são suas necessidades em relação ao exercício de cidadania. Embora extrapolem o âmbito profissional, tais aspectos ao mesmo tempo o influenciam, uma vez que ilustram que a experiência destas mulheres enquanto cidadãs de direito não é plena, que dirá suas experiências laborais.

\footnotetext{
"Humilhação dentro de casa, da própria família, é a negação da própria sociedade dizendo que a gente está possuída por algum demônio ou doente" (Entrevistada 1)

"Policial que te olha, te xinga, quer te bater, manda você para correr" (Entrevistada 4)

"Ainda não consegui fazer a retificação dos meus documentos. É muito difícil!" (Entrevistada 4)

"Fomos procurar o centro de referência para começar a fazer corretamente porque eu tinha dado início de trombose na perna por altas dosagens" (Entrevistada 5)

"Tem lugar que eu vou e preciso usar o banheiro eles mandam usar o masculino" (Entrevistada 4)
}

\section{Planejamento de carreira e suporte}

Perante a situação de fragilidade do processo de empregabilidade e as barreiras encontradas para se inserirem no mercado de trabalho, o planejamento de carreira junto ao público trans $e$ travesti poderia ser considerado uma das formas de transcender as dificuldades supracitadas. Contudo, nenhuma pesquisa empírica que investigasse a importância desse planejamento e do suporte necessário para tal em carreiras de mulheres transexuais e travestis foi encontrada na literatura até o momento. Desse modo, neste estudo buscamos compreender qual a noção de planejamento de carreira que as entrevistadas apresentavam, quantas delas o realizavam e como o faziam, e em casos negativos, porque não planejavam suas carreiras.

\section{Planejamento é importante, mas nem todas fazem}

Todas as participantes da pesquisa consideraram de suma importância a prática do planejamento de carreira, porém apenas três delas o fazem efetivamente. Dentre elas, duas o empreendem por meio da busca ativa/estudo, e três através de oportunidades que vão surgindo, como explicitado em algumas de suas falas:

\footnotetext{
"Acho extremamente importante a gente planejar" (Entrevistada 5)

"Eu planejo sim. Tenho duas ou três opções. Eu leio bastante e estudo bastante" (Entrevistada 2)
}

"Na minha área eu busco cursos. O planejamento tinha que ser feito por mim mesma conforme ia surgindo às oportunidades" (Entrevistada 3)

\section{Sem suporte não há planejamento}

Um fator importante no planejamento de carreira é o apoio social. A rede de suporte se refere à rede de familiares e amigos que aconselham, dão assistência e encorajam os indivíduos em suas decisões, além de auxiliarem no enfrentamento do estresse (Anderson; Goodman; Schlossberg, 2012). Adams, Cahill\&Ackerlind (2005) e Slebarska et al. (2009) consideraram o apoio social extremamente relevante para o trabalho e comportamento de busca de emprego. Assim, 
questionamos as entrevistadas acerca do suporte recebido para planejarem suas carreiras e do suporte que gostariam de receber. Delas, quatro afirmaram nunca terem recebido suporte para qualquer planejamento em relação à carreira, e uma alegou ter recebido suporte apenas dos amigos.

"Nunca, nunca recebi nenhum tipo de suporte para isso" (Entrevistada 1)

"Na verdade eu nunca planejei minha carreira porque nunca tive suporte" (Entrevistada 5)

Referente ao suporte que gostariam de receber para planejar a carreira, três citaram instituições de ensino, como universidades e escolas, duas apontaram os professores, e outras duas mencionaram assessoria profissional.

"Suporte vindo da Universidade e dos professores" (Entrevistada 2)

"Penso que os professores deviam auxiliar mais" (Entrevistada 4)

"Assessoria seria o principal suporte que me auxiliaria e muito na minha carreira" (Entrevistada 5)

Similarmente, no estudo de Brown et al (2012), os participantes demonstraram o desejo de buscarem formação e treinamento, além de realizarem aconselhamento para avaliarem seus interesses e habilidades a fim de alcançarem carreiras em campos e organizações que não tolerem discriminação no local de trabalho. Segundo Krieshok (1998, apud Velozo; Dutra, 2014), o suporte tem a função de auxílio às decisões e pode dar-se por meio de cursos, oficinas e assessoria profissional, colaborando para uma melhor assertividade na decisão. Nesse sentido, compreende-se que ONG's e universidades poderiam investir mais esforços no sentido de propor projetos e iniciativas que enfatizem a preparação para inserção profissional de público trans e travesti, focando na superação de barreiras e realização das escolhas profissionais. Além disso, faz-se necessário que mais empresas estabelecem percentuais de ocupação de suas vagas (cotas) direcionados a pessoas desta população, além de desenvolver programas de inclusão específicos para estas mulheres (e homens). Desta maneira, poder-se-ia vislumbrar que no futuro mais mulheres transexuais e travestis possam realizar suas escolhas profissionais e concretizar seus planos de carreira, mitigando o aparente fatídico destino do trabalho subalterno ou da prostituição e efetivamente incluindo essas pessoas na sociedade.

\section{Conclusão}

A partir do mapeamento da inserção profissional, das barreiras e do planejamento de carreira realizado pelas participantes, pode-se compreender como essas mulheres podem vir a realizar escolhas de carreira baseadas em seus interesses, valores, habilidades e preferências. Os resultados dessa pesquisa contribuem para o mapeamento das barreiras existentes para o desenvolvimento de carreira junto a público, assim como para enfatizar a necessidade do suporte a ser dado a tal população, para que assim tenham melhores condições de inserção no mercado de trabalho. Dessa maneira, são apresentadas evidências que podem subsidiar programas de incentivo ou até mesmo políticas públicas de inclusão social direcionadas a pessoas trans e travestis, assim como a construção de treinamentos e programas de orientação de carreira que considerem os desafios $e$ peculiaridades da vida pessoal e profissional dessa população.

Este estudo traz contribuições teóricas visto que corrobora com resultados apontados pela literatura, porém representa uma investigação pioneira referente ao tema, especialmente no tocante à área de planejamento de carreira, que apresenta grande escassez de estudos com tal público. Uma importante contribuição social é que o público participante representa uma classe social minoritária, historicamente discriminada e excluída socialmente; portanto, dar voz a essas pessoas ressalta não apenas a necessidade de envidar esforços para de fato incluí-los na sociedade, como também possibilita a consideração de modos de transcender as barreiras impostas a elas. Além disso, uma outra implicação prática (e também política) é a de apontar caminhos para enxergar essas mulheres para além do mundo dos empregos precarizados e da prostituição. Isto representou um dos objetivos subjacentes deste artigo, o que foi alcançado uma vez que apenas uma das participantes 
apontou estar na prostituição, sinalizando a existência de alternativas em relação à inserção profissional dessas mulheres.

Em relação ao campo de estudos sobre gênero e sexualidade, ainda é escassa a pesquisa referente às relações entre tais questões $e$ a inserção no mercado de trabalho $e$ o planejamento de carreira. Portanto, ressalta-se a importância de ir além da investigação da sexualidade e da transição sexual, observando a demanda por pesquisas que apontem estratégias que contribuam para o afastamento da limitação dessa população a profissões estereotipadas e de baixa renda. Dessa forma, destaca-se a urgência da inserção desse público na sociedade como seres de pleno direito, cujas opções profissionais sejam tão variadas quanto a de outras pessoas.

No tocante à Psicologia Organizacional e do Trabalho, este estudo extrapola os muros das organizações, uma vez que investiga carreira dos indivíduos para além daquelas, ampliando a concepção de experiência laboral $e$ atendendo aos vetores de transformação da área propostos por Bastos, Yamamoto e Rodrigues (2013). Entretanto, os resultados obtidos podem contribuir para alertar as empresas sobre suas práticas de discriminação e exclusão para com o público trans $e$ travesti, principalmente nos processos seletivos. A aproximação dessas pessoas com o mercado formal de trabalho apresenta-se como urgente e necessária, portanto, o presente estudo pode também contribuir para subsidiar ou promover iniciativas de gestão da diversidade nas organizações.

Contudo, o presente estudo apresenta limitações no que diz respeito ao número reduzido de participantes. Apesar de se ter atingido o ponto de saturação, compreende-se que um número maior de participantes poderia contemplar questões distintas das aqui identificadas. Adicionalmente, o presente estudo não contempla mulheres em posições de poder, assim como não acessa camadas inferiores no quesito escolaridade, o que também pode ter limitado o espectro de respostas. Também seria oportuno englobar participantes em idades mais avançadas, principalmente ao se considerar a baixa expectativa de vida da população transexual no Brasil, que gira em torno de 35 anos (Almeida; Vasconcellos, 2018). Portanto, estudos futuros deveriam contemplar tais aspectos, assim como também outras variáveis ligadas a comportamentos de carreira, tais como adaptabilidade, autoeficácia na carreira e realização profissional. Por fim, seria relevante que pesquisas quantitativas e longitudinais fossem conduzidas, de maneira a permitir a generalização dos resultados e aumentar a atenção para as demandas específicas do público para o qual se voltou nossas análises.

\section{Referências bibliográficas}

ADAMS, Eve M.; CAHILL, Betsy J.; ACKERLIND, Stacy J. A qualitative study of Latino lesbian and gay youths' experiences with discrimination and the career development process. Journal of Vocational Behavior, v. 66, n. 2, 2005, pp.199-218.

ALMEIDA, Cecília Barreto de; VASCONCELLOS, Victor Augusto. Transexuais: transpondo barreiras no mercado de trabalho em São Paulo?. Revista Direito GV, v. 14, n. 2, 2018, pp.302-333.

ANDERSON, Mary; GOODMAN, Jane; SCHLOSSBERG, Nancy K. Counseling Adults in Transition: Linking Schlossberg, Theory With Practice in a Diverse World. Springer Publishing Company, 2011.

ARAÚJO, Edna Torres de et al. Fatores de decisão de carreira durante a graduação. Revista de Carreiras e Pessoas, v. 8, n. 2, 2018, pp.151-171.

ASSOCIAÇÃO Nacional de Travestis e Transexuais - ANTRA. Cartilha Gênero [//antrabrasil.org/relatorios/ acesso em: 11 out. 2018].

BARDIN, Laurence. Análise de Conteúdo. Lisboa- Portugal, LDA, 2009.

BANDURA, Albert. Self-efficacy: The exercise of control. New York, NY, W. H. Freeman and Company, 1997.

BANDURA, Albert. Social foundations of thought and action. NJ, Englewood Cliffs, 1986.

BARBOSA, Bruno Cesar. "Doidas e putas": usos das categorias travesti e transexual. Sexualidad, Salud y Sociedad, n. 14, 2013, pp.352-379. 
BASTOS, A. V. B.; YAMAMOTO, O. H.; RODRIGUES, A. C. A. Compromisso social e ético: desafios para a atuação em Psicologia Organizacional e do Trabalho. In: BORGES, L. O.; MOURÃO, L. (org.). O trabalho e as organizações: atuações a partir da Psicologia. Porto Alegre, Artmed, 2013, v. 1, pp.25-52.

BROWN, Chris et al. The career experiences of male-to-female transsexuals. The Counseling Psychologist, v.40, n.6, 2012, pp.868-894.

BUDGE, Stephanie L.; TEBBE, Esther N.; HOWARD, Kimberly AS. The work experiences of transgender individuals: Negotiating the transition and career decision-making processes. Journal of Counseling Psychology, v. 57, n. 4, 2010, pp.377.

BUTLER, Judith. Problemas de gênero: feminismo e subversão da identidade. Rio de Janeiro, Civilização Brasileira, 2003.

CARVALHO, Evelyn Raquel. Eu quero viver de dia: uma análise da inserção das transgêneros no mercado de Trabalho. Anais do VII Seminário Fazendo Gênero, v. 7, 2006 [http://www.fazendogenero.ufsc.br/7/ - acesso em 10 dez 2018].

CHAVEZ-KORELL, Shannon; JOHNSON, Les T. Informing counselor training and competente counseling services through transgender narratives and the transgender community. Journal of LGBT issues in counseling, v. 4, n. 3-4, 2010, pp.202-213.

CHOPE, Robert; STROM, Laura. Critical Considerations in career and employment counseling with transgender clients, 2008.

CHOWDHURY, Nilima; GIBSON, Kerry. Thisis (still) a man's world: Young professional women's identity struggles in gendered workplaces. Feminism \& Psychology, v. 29, n.4, 2019, pp.1-19.

CRITES, John. Vocational psychology. New York, McGraw-Hill, 1969.

DIAS, Jossiani Augusta Honório; BERNARDINELI, Muriana Carrilho. O Transexual e o Direito de Acesso ao Mercado de Trabalho: Do Preconceito à Ausência de Oportunidades. Revista de Gênero, Sexualidade e Direito, v. 2, n. 2, 2016, pp.243-259.

DUTRA, J. S. Administração de Carreira: uma proposta para repensar a Gestão de Pessoas. São Paulo, Atlas, 2010.

FIGUEIREDO, Cláudia Roberta Leite Vieira. Essa pele que habito - reflexões sobre transexualidade, discriminação e abuso às garantias constitucionais no contexto do direito do trabalho. JURIS-Revista da Faculdade de Direito, v. 27, n.1, 2017, pp.67-80.

HUMAN RIGHTS CAMPAIGN FOUNDATION. Transgender issues in the workplace: A tool for managers. Washington, DC, Autor, 2004 [https://www.hrc.org/hrc-story/hrc-foundation - acesso em: 15 dez. 2017].

KAFFER, Karen Ketlin et al. A Transexualidade e o mercado formal de trabalho: Principais dificuldades para a inserção profissional. Anais do Congresso Brasileiro de Estudos Organizacionais, 2016 [https://anaiscbeo.emnuvens.com.br/cbeo/article/view/52 - acesso em: 10 dez. 2018].

LENT, Robert. W.; BROWN, Steven. D.; HACKETT, Gail. Contextual supports and barriers to career choice: A social cognitive analysis. Journal of counseling psychology, v.47, n.1, 2000, pp.36.

LENT, Robert W.; BROWN, Steven D.; HACKETT, Gail. Toward a unifying social cognitive theory of career and academic interest, choice, and performance. Journal of vocational behavior, v. 45, n. 1, 1994, pp.79122.

MALSCHITZKY, N. A importância da orientação de carreira na empregabilidade. $F A E$, v.15, n.1, 2012, pp.150-165.

MARTENDAL, Laura. Experiência(s) Profissionai(s)? Relatos de mulheres transexuais. 2015. Trabalho de Conclusão de Curso. Coordenadoria de Estágios e Monografias do Departamento de Serviço Social da Universidade Federal de Santa Catarina, 2015.

MIANO, Vítor Yoshihara; VIEIRA, Fernando de Oliveira. Perspectivas de carreira dos formandos de Administração de uma IFES. Revista Pensamento Contemporâneo em Administração. Rio de Janeiro, v. 6, n.1, 2012, pp.72-90. 
NORONHA, Ana Paula Porto; LAMAS, Karen Cristina Alves. Preditores do comprometimento com a carreira e sua relação com o desempenho acadêmico em universitários. Revista Pensamento Psicológico, São Paulo, v. 12, n. 2, 2014, pp.65-78.

NUNES, Juliane Vargas et al. A pesquisa qualitativa apoiada por softwares de análise de dados: uma investigação a partir de exemplos. Fronteiras-estudos midiáticos, v. 19, n. 2, 2017, pp.233-244.

OURIQUE, L. R. Auto-eficácia e personalidade no planejamento de carreira de universitários. Dissertação de mestrado, Universidade Federal do Rio Grande do Sul, Porto Alegre, RS, 2010.

O'NEIL, Maya Elin; MCWHIRTER, Ellen Hawley; CEREZO, Alison. Transgender identities and gender variance in vocational psychology: Recommendations for practice, social advocacy, andresearch. Journal of Career Development, v.34, n.3, 2008, pp.286-308.

PEDREIRA, Lucas Jorge; SANTOS, Heliane Berlato dos. Da marginalidade à busca pelo sucesso: carreiras de $\begin{array}{lllll}\text { pessoas transexuais na } 29^{\circ} & \text { atualidade. }\end{array}$ [http://2018.enangrad.org.br/pdf/2018_JUNIOR216.pdf - acesso em: 10 abr. 2019].

PERANTONI GUIGEN, Amanda et al. Fonoaudiologia como opção de carreira universitária: estudo exploratório. Revista CEFAC, v. 16, n. 3, Bauru - SP, 2014, pp. 974-984.

RONDAS, Lincoln de Oliveira; MACHADO, Lucília Regina de Souza. Inserção profissional de travestis no mundo do trabalho: das estratégias pessoais às políticas de inclusão. Pesquisa e práticas psicossociais, v.10, n.1, 2015, pp.192-205.

SEGNINI, Liliana Rolfsen Petrilli. Educação e trabalho: uma relação tão necessária quanto insuficiente. São Paulo em Perspectiva, São Paulo, v.14, n.2, 2000, pp.72-81.

SOUZA, D.; COSTA, B.; RODRIGUES, E. A inserção de pessoas transexuais e travestis no mercado de trabalho. Anais do XII Congresso Nacional de Excelência em Gestão, Rio de Janeiro, 2016 [https://www.inovarse.org/sites/default/files/T16_029.pdf - acesso em 15 mar 2019].

SUPER, Donald. E.; SAVICKAS, Mark. L.; SUPER, Charles. M. The life-span, life-space approach to careers. Carreer choice and development, San Francisco, Jossey-Bass, 1996, pp.121-178.

SCHILT, Kristen. Just one of the guys? How trans men make gender visible at work. Gender and Society, v.20, n. 4, 2006, pp.465-490.

SCHILT, Kristen; CONNELL, Catherine. Do work place gender transitions make gender trouble?.Gender, Work \& Organization, v.14, n. 6, 2007, pp.596-618.

ŚLEBARSKA, Katarzyna; MOSER, Klaus; GUNNESCH-LUCA, George. Unemployment, social support, individual resources, and job search behavior. Journal of employment counseling, v. 46, n. 4, 2009, pp.159-170.

SWANSON, Jane L.; WOITKE, Mary B. Theory Into Pratice in Career Assessement for Women: Assessment and Interventions Regarding Perceived Career Barriers. Journal of Career Assessement, v.4, n. 5, 1997, pp.443-462.

SWANSON, Jane L.; TOKAR, David M. College students' perceptions of barriers to career development. Journal of Vocational Behavior, v.38, 1991, pp.92-106.

TEIXEIRA, Flávia do Bonsucesso. L' Itália dei Divietti: entre o sonho de ser europeia e o babado da prostituição. cadernos pagu (31), Campinas, SP, Núcleo de Estudos de Gênero-Pagu/Unicamp, 2008, pp.275-308.

VELOSO, Elza Fátima Rosa; DUTRA, Joel Souza. A tomada de decisões na transição de carreira: uma proposta de associação de conceitos. Revista Administração em Diálogo, v. 16, n. 2, 2014, pp.216-245. 